\title{
SUBSTITUIÇÃO DOS GRÃOS SECOS DE MILHO PELA SILAGEM DE GRÃOS ÚMIDOS DE MILHO PARA VACAS DA RAÇA HOLANDESA EM LACTAÇÃO
}

\author{
Amanda Panichi' ${ }^{1}$, Ciniro Costa ${ }^{1}$, Gercilio Alves de Almeida Junior ${ }^{2}$, Paulo Roberto \\ de Lima Meirelles ${ }^{1}$, Marina Gabriela Berchiol da Silva' ${ }^{1}$, João Paulo Franco da \\ Silveira ${ }^{1}$
}

\author{
1 FMVZ-UNESP \\ 2 UFES \\ Correspondência: Marina Silva: gabiberchiol@hotmail.com
}

\begin{abstract}
RESUMO: Com o objetivo de avaliar os efeitos da substituição dos grãos secos de milho (GSM) pela silagem de grãos úmidos de milho (SGUM) sobre a produção e composição do leite, foram utilizadas cinco vacas da raça Holandesa, primíparas de 112 dias pós-parto em média, confinadas em Tie Stall, por 70 dias. Utilizou-se cinco rações de acordo com o NRC para 17,5\% PB (MS) e 2,4 Mcal $\mathrm{EM} / \mathrm{kg} \mathrm{MS}$, na relação 40:60 de volumoso e concentrado contendo farelo de soja, silagem de cana de açúcar e feno à níveis de substituição dos GSM pela SGUM nos tratamentos: 1) 0\%; 2) $25 \%$; 3 ) $50 \%$; 4) $75 \%$ e 5) $100 \%$. A produção de leite e o consumo de matéria seca (CMS) foram registrados diariamente. Os animais foram ordenhados diariamente 6:00 e 18:00 h, sendo as amostras de leite coletadas nas ordenhas consecutivas de cada fase experimental de 14 dias (quatro dias de coleta). O delineamento experimental utilizado foi o Quadrado Latino $5 \times 5$ e os dados analisados pelo programa estatístico SAS. O peso corporal $(508 \mathrm{~kg})$, produção de leite $(23,6 \mathrm{~kg})$, produção de leite corrigida $(22,7 \mathrm{~kg})$, CMS (17,13 kg), não apresentaram diferenças significativas, porém os consumos de fibra em detergente neutro $(6,67 \mathrm{~kg})$, em detergente ácido $(3,39 \mathrm{~kg})$, eficiência alimentar para produção de leite $(1,41 \mathrm{~kg}$ leite/dia) e o nitrogênio uréico $(17,67 \mathrm{mg} / \mathrm{dL})$ apresentaram diferença, indicando desta forma que a SGUM é mais eficiente que os GSM na dieta de vacas em lactação por não alterar a produção e composição do leite.
\end{abstract}

Palavras-chave: composição do leite; processamento do milho; produção de leite

\section{SUBSTITUTION OF DRY SHELLED CORN BY THE HIGH MOISTURE CORN SILAGE FOR LACTATING HOLSTEIN COWS}

\begin{abstract}
In order to evaluate the effects of replacement of dried corn (GSM) for silage moisture corn (HMCS) on production and milk composition were used five Holstein cows, primiparous with a mean of 112 days post delivery, confined in Tie Stall, for 70 days. We used five diets according to $\mathrm{NRC}$ to $17.5 \% \mathrm{CP}$ (DM) and $2.4 \mathrm{Mcal} / \mathrm{kg} \mathrm{DM}$, the 40:60 ratio of roughage and concentrate containing soybean meal, sugar cane silage and hay and substitution levels of the GSM HMCS the following treatments: a) $0 \%$, 2) $25 \%$, 3) $50 \%$, 4) $75 \%$ and 5) $100 \%$. Milk production and dry matter intake (DMI) were recorded daily. The animals were milked daily 6:00 and 18:00 h, and milk samples collected from consecutive milkings of each experimental period of 14 days (four days of collection). The experimental design was a $5 \times 5$ Latin square and the data analyzed by the statistical program SAS. Body weight $(508 \mathrm{~kg})$, milk $(23.6 \mathrm{~kg})$, corrected milk $(22.7 \mathrm{~kg})$, DMl $(17.13 \mathrm{~kg})$ showed no significant difference, but the intakes of neutral detergent fiber $(6.67 \mathrm{~kg})$, and detergent acid $(3.39 \mathrm{~kg})$, feed efficiency for the production of milk (milk $1.41 \mathrm{~kg} /$ day) urea nitrogen $(17.67 \mathrm{mg} / \mathrm{dL}$ ) differ, thus indicating that HMCS is more efficient than GSM in the diet of dairy cows not alter the production and milk composition.
\end{abstract}

Key Words: : milk composition; corn processing; milk yield 


\section{INTRODUÇÃO}

As mudanças impostas à pecuária leiteira no Brasil, principalmente após a abertura ao mercado externo, ocorrida na década de 90, fizeram com que um novo perfil se desenhasse para o setor. Sobretudo um dos principais gargalos na exploração desta, ainda é o custo de produção já que o produto leite tem apresentado desde então, baixos preços pagos aos produtores.

O conhecimento dos fatores que afetam a composição nutricional do leite pode gerar pelo menos dois benefícios importantes ao produtor. Em primeiro lugar trata-se de uma ferramenta importante na avaliação nutricional da dieta, podendo revelar informações sobre a eficiência, utilização dos nutrientes e saúde animal. Em segundo lugar, para atender as demandas por qualidade do leite, as indústrias têm procurado matéria prima de boa qualidade, exigindo profissionalização dos produtores, pois em alguns países os programas de pagamento são por qualidade e não mais por volume.

A principal fonte de amido na dieta dos ruminantes vem dos grãos de cereais, principalmente do milho, portanto, sua ótima utilização é fundamental para melhorar a eficiência da produção animal. Vacas especializadas requerem suplementação de alimentos concentrados, portanto faz-se necessário a busca por alimentos alternativos aos grãos secos de milho (GSM), que é a principal fonte de energia das rações.

Diante disso, a substituição dos GSM pela silagem de grãos úmidos de milho (SGUM) pode trazer vantagens e benefícios múltiplos, na colheita, armazenamento, conservação, locais de digestão que foram amplamente discutido por Owens et al. (1986); Jobim et al. (2003), e confirmado por Jasper et al. (2009) ao avaliarem o custo por hectare da SGUM e GSM, que resultou em $8,8 \%$ de economia no processo de ensilagem dos grãos úmidos de milho.

No entanto, no Brasil, não existem trabalhos científicos avaliando os possíveis benefícios do uso da SGUM na alimentação de vacas leiteiras, embora a mesma já seja utilizada para esta finalidade em algumas regiões do país. Dessa forma objetivou-se avaliar a substituição dos GSM pela SGUM na produção e composição do leite de vacas da raça holandesa em lactação.

\section{MATERIAL E MÉTODOS}

O experimento foi conduzido no setor de Bovinocultura Leiteira da Fazenda Experimental Marcello Mesquita Serva da Universidade de Marília (UNIMAR). Foram utilizadas cinco vacas da raça Holandesa (HPB), primíparas lactantes com média de 112 dias pós-parto, produção de leite média de $24,3 \mathrm{~kg} / \mathrm{dia}$ e peso médio de $508 \mathrm{~kg}$ estimado com fita barimétrica, ao início e final de cada fase experimental (a cada 14 dias). Os animais receberam uma dose de vitamina $A, D$ e $E$ antes de iniciar as avaliações.

As vacas foram confinadas em galpão coberto e equipado com aspersores, em instalações tipo Tie Stall, alojadas em baias individuais $(2,50$ x 1,20 m) com cama de areia, providas de comedouros e bebedouros individuais. As vacas foram soltas duas horas por dia para se exercitarem em piquete anexo às instalações.

O período experimental teve duração total de 70 dias, dividido em cinco fases de 14 dias cada, onde os primeiros dez dias de cada fase experimental foram utilizados para adaptação dos animais nos tratamentos e os quatro últimos dias restantes, para coletas de dados.

Foram avaliadas cinco dietas, adotando-se a relação volumoso:concentrado de 40:60, na 
base da MS. As rações experimentais foram balanceadas para $17,5 \%$ PB (MS) e 2,4 Mcal EM/kg MS, de acordo com o NRC (2001), contendo como volumoso silagem de cana-de-açúcar (24,4\% MS) e feno de coast-cross (Cynodon dactylon) $\quad(14,5 \% \quad \mathrm{MS}), \quad \mathrm{e}$ os concentrados constituídos de farelo de soja $(24,2 \%$ MS), grãos secos de milho (GSM) e/ou silagem de grãos úmidos de milho (SGUM). Níveis de substituição dos GSM pela SGUM estão descritos nos tratamentos, com base na MS: 1) $0 \%$; 2) 25\%; 3) 50\%; 4) 75\%; 5) 100\% (Tabela 1). Na Tabela 2 encontra-se a composição química dos ingredientes e das rações experimentais.

Tabela 1 - Composição percentual dos ingredientes (\%MS)

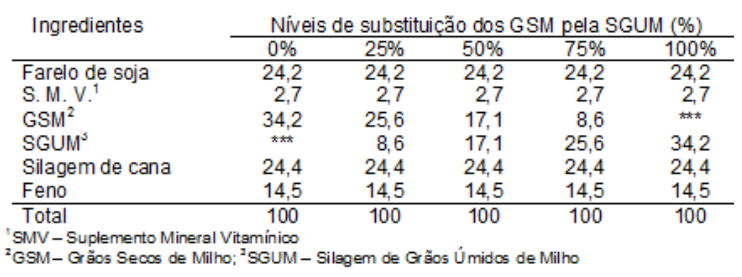

Tabela 2 - Composição química dos ingredientes e das rações experimentais com niveis de substituiçãa dos grãos secos de milhó pela silagem de grãos úmidos de milho (\%MS)

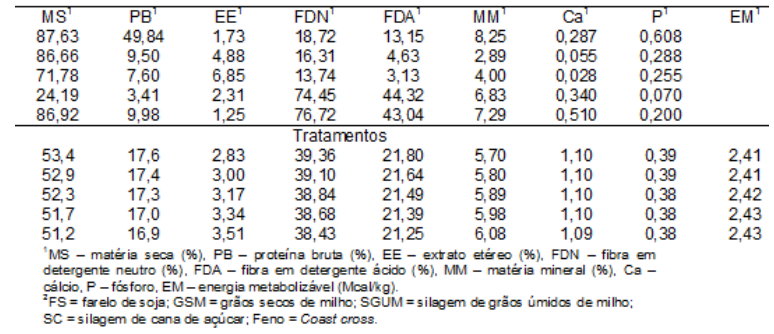

Para a silagem de grãos úmidos de milho, procedeu-se à colheita logo após o estádio de maturação fisiológica, com umidade de $28 \%$. Após a colheita, os grãos foram esmagados utilizando-se ensiladora para silo "bag" e armazenados em tambores plásticos com capacidade para $200 \mathrm{~kg} / \mathrm{cada}$, obedecendo à sistemática de compactação e de vedação do processo de ensilagem e manejo do silo. O feno, farelo de soja e os GSM foram finamente moídos para serem adicionados às rações. O suplemento mineral vitamínico (SMV) apresentava em sua composição: Ca: $156,00 \mathrm{~g}$; P: 51,00g; S: 20,00g; Mg: 33,00g; $\mathrm{Na}$ : 93,00g; K: 28,00g; Co: 30,00mg; Cu: 400,00mg; Cr: 10,00mg; Fe: $2.000,00 \mathrm{mg}$; I: 40,00mg; Ma: 1,350,00mg; Se: 15,00mg; F: 510,00mg; Zi: $1.1700,00 \mathrm{mg}$; Vit. A: $135.000,00 \mathrm{Ul}$; Vit. D3: $68.000,00 \mathrm{UI}$; Vit E: 450,00 UI.

$\mathrm{O}$ arraçoamento foi parcelado em três vezes ao dia (6:30, 13:30 e 18:30 h) ad libitum, na forma de ração mista total objetivando sobras de $10 \%$ do oferecido para evitar limitação do consumo. Por ocasião do fornecimento da alimentação, as quantidades de volumoso e concentrado foram pesadas separadamente e misturadas em um misturador horizontal, visando a obtenção da ração completa de cada animal. As amostras de alimentos foram coletadas no final de cada fase experimental para posteriores análises laboratoriais. Os dados de CMS por animal/dia foram obtidos pela diferença entre a quantidade de MS fornecida e as sobras.

As amostras de alimento foram conservadas congeladas a $-10^{\circ} \mathrm{C}$. Após o término do período experimental, foram descongeladas e secas em estufas com ventilação forçada (55$60^{\circ} \mathrm{C}$ ), por 72 horas, para determinação da MS e, posteriormente, processadas em moinho tipo Willey, provido de peneira com crivos de $1 \mathrm{~mm}$. Foram analisadas MS ( $105^{\circ} \mathrm{C}$ durante $5 \mathrm{~h}$ ), PB e extrato etéreo (EE) de acordo com o AOAC (1990), e FDN e FDA de acordo com Van Soest et al. (1991).

Os animais foram submetidos a duas ordenhas diárias (6:00 e 18:00 h), e a produção de leite registrada diariamente, até o final do período experimental. Para o cálculo da produção de leite corrigido para $4 \%$ de gordura, adotou-se a fórmula proposta pelo NRC (2001): LCG $=0,4(\mathrm{~kg}$ de leite) +15 ( $\mathrm{kg}$ de gordura). Para 0 cálculo de eficiência alimentar da produção de leite (EAPL) empregou-se a seguinte fórmula: $\mathrm{EAPL}=$ valores médios da Produção de Leite em kg/dia 
$(\mathrm{PL}) /$ Consumo de Matéria Seca em $\mathrm{kg} / \mathrm{dia}(\mathrm{CMS})$. Em relação ao cálculo de eficiência alimentar da produção de leite corrigida (EAPLC), seguiu-se o mesmo raciocínio. As amostras de leite foram coletadas diariamente nos quatro últimos dias de cada fase experimental em ordenhas consecutivas, por meio de um dispositivo acoplado à ordenhadeira, sendo preservada em frascos de $50 \mathrm{~mL}$ com o conservante Bronopo $\AA$ para posterior análise dos teores de gordura, proteína, lactose, sólidos totais; nitrogênio uréico e contagem de células somáticas (CCS) na Clínica do Leite ESALQ. As determinações de acidez titulável em Graus Dornic e Densidade foram realizadas no laboratório da UNIMAR por meio do Termolactodensímetro e Acidez pelo método de Dornic.

$O$ delineamento experimental utilizado foi o de Quadrado Latino $5 \times 5$ e os dados analisados pelo procedimento GLM do software estatístico SAS versão 4.6 (1996). As diferenças estatísticas dos parâmetros foram determinadas utilizando-se 0 seguinte modelo matemático:

$$
Y_{i j k}=m+l_{i}+c_{j}+t_{k(j) ~}+e_{i j k}
$$

Yijk $=$ valor observado na unidade experimental que recebeu o tratamento $\mathrm{k}$ (na linha i e coluna j); $\mathrm{m}=$ média geral; $\mathrm{li}=$ efeito da vaca $\mathrm{i} ; \mathrm{cj}=$ efeito do período j; tk(ij) = efeito do tratamento $\mathrm{k}$ aplicado na vaca $\mathrm{i}$ e período $\mathrm{j} ; \mathrm{e}_{\mathrm{ijk}}=$ erro aleatório (resíduo).

Os dados foram analisados no nível de $5 \%$ de significância. Regressões foram utilizadas para definir os efeitos linear (L), quadrático $(Q)$, cúbico (C) e quártico (Qt), para as variáveis que apresentaram diferença.

\section{RESULTADOS E DISCUSSÃO}

As médias do $P C$, produção de leite $(\mathrm{PL})$, produção de leite corrigida para $4 \%$ de gordura (PLC), CMS, CFDN, CFDA, eficiência alimentar da produção de leite (EAPL) e eficiência alimentar da produção de leite corrigida (EAPLC) são apresentadas na Tabela 3. Tabela 3 - Médias e coeficientes de variação (CV\%) das características de PC,
produção de leite, consumo e eficiência alimentar de vacas da raça

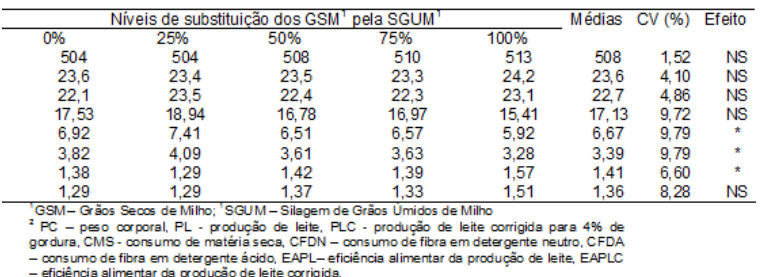

Não foi observada diferença para o PC (508 kg), uma vez que, no início do experimento as vacas já estavam com 112 dias pós-parto, momento este posterior ao período de balanço negativo de energia que ocorre ao redor do pico de lactação. Alterações no peso são mais comuns nessas primeiras semanas de lactação.

Não houve efeito das rações experimentais sobre a $\mathrm{PL}(23,6 \mathrm{~kg} / \mathrm{dia})$, ocorrendo o mesmo com a PLC para $4 \%$ de gordura $(22,7 \mathrm{~kg} / \mathrm{dia})$. Esta ausência de aumento na PL e PLC para os níveis de inclusão de silagem de grãos úmidos de milho (SGUM) em substituição aos grãos secos de milho (GSM) no concentrado possivelmente pode ser explicada pelo fato do pico de lactação ter ocorrido antes do início do trabalho. Provavelmente 0 efeito da adição da SGUM seria mais efetivo para o período anterior ao pico de lactação. Broderick et al. (2002) não observaram diferenças na produção e na composição do leite, e na eficiência alimentar quando a silagem de grãos úmidos de milho substituiu o milho seco em dietas para vacas confinadas. Segundo os autores, a digestão pósruminal do amido no tratamento com milho seco compensou a alta digestibilidade ruminal apresentada pelas vacas que consumiram milho úmido. Oba et al. (2003) também não encontraram diferenças $(P>0,05)$ na produção e na composição do leite, ao utilizarem milho seco ou silagem de grãos úmidos de milho em dietas para vacas leiteiras com baixa porcentagem 
de amido ( $21 \%$ da matéria seca), porém observaram diminuição $(\mathrm{P}<0,05)$ para produção de leite e quando a silagem de grãos úmidos substituiu o milho seco em dietas com alta porcentagem de amido (33\%). Contudo, esses autores utilizaram como volumosos, a silagem de milho (alimento também rico em amido) com $50 \%$ da matéria seca do volumoso e a silagem de alfafa com $50 \%$ da matéria seca do mesmo.

Provavelmente, a utilização de silagem de cana-de-açúcar como volumoso principal e não a silagem de milho, tenha provido elevado aporte de carboidratos de alta degradação ruminal (mono e dissacarídeos e ácidos orgânicos) na dieta total do presente experimento. Desta forma, a contribuição da silagem de grãos úmidos de milho em aumentar a digestibilidade ruminal do amido e consequentemente a produção de AGV's no rúmen, pode não ter sido relevante para intensificar 0 metabolismo microbiano no local.

Não houve efeito das rações experimentais sobre o CMS, que apresentou média de 17,13 kg/dia sendo de $3,37 \%$ do $\mathrm{PC}$, o que seria de se esperar, considerando-se que as dietas totais apresentaram valores muito próximos para FDN (38,44 a 39,36\%), conforme pode ser observado na Tabela 2. A fração fibrosa da dieta atua limitando consumo e neste caso, algum eventual efeito da SGUM em conferir maior degradabilidade ruminal do amido, maior atividade microbiana no rúmen e maior digestibilidade total da dieta, não foi observado. Chandler et al. (1974) comparando GSM (17,89 kg/dia) com SGUM (17,99 kg/dia) também não encontraram diferença para CMS. O mesmo comportamento foi observado por San Emeterio et al. (2000).

Houve efeito quadrático para 0 CFDN (6,67 kg/dia) e CFDA (3,39 $\mathrm{kg} / \mathrm{dia})$ como pode ser observado nas Figuras 1 e 2, respectivamente. $\mathrm{O}$
CFDN foi maior quando os GSM foram substituídos em $25 \%$ pela SGUM. Este resultado pode ser oriundo do maior estímulo ao consumo, tendo em vista que a SGUM apresenta maior digestibilidade ruminal quando comparada aos GSM (Owens et al., 1986). Decrescendo nos demais níveis de substituição (50, 75 e 100\%), possivelmente devido a uma limitação química, uma vez que com o aumento da digestibilidade a demanda energética do animal foi suprida. No entanto, a diferença observada entre o maior valor numérico (25\% SGUM) e o menor valor (100\% SGUM) foi de $20 \%$. Por outro lado, Ekinci \& Broderick (1997) não encontraram diferença para o CFDN e CFDA quando as vacas foram alimentadas com GSM, SGUM e silagem de espiga de milho.

Com a mudança nos conceitos sobre a eficiência do uso do amido pelos ruminantes, está comprovado 0 melhor desempenho dos animais quando alimentados com amido de alta degradação ruminal. Os resultados médios observados para EAPL $(1,41)$ demonstram melhor aproveitamento dos nutrientes da dieta total para o nível de substituição de $100 \%$ dos GSM pela SGUM (Figura 3). Owens et al. (1986), já haviam ressaltado que os nutrientes da SGUM são melhor aproveitados no rúmen quando comparados aos nutrientes do GSM. Os valores encontrados para o nível de substituição de $25 \%$ dos GSM resultaram na menor EAPL do presente estudo, pois mesmo tendo um maior consumo de nutrientes este foi menos aproveitado, provavelmente devido ao alto CFDN.

O mesmo comportamento foi observado por Clark \& Harshbager (1972) ao encontraram diferença para EAPL quando ofereceram GSM $(1,19 \mathrm{~kg}$ de leite/dia) e SGUM $(1,30 \mathrm{~kg}$ de leite/dia) para vacas em lactação, sendo a SGUM mais eficiente do que os GSM. Por outro lado, Clark et al. (1974) e 
Enkinci \& Broderick (1997) não encontraram diferença para EAPL.

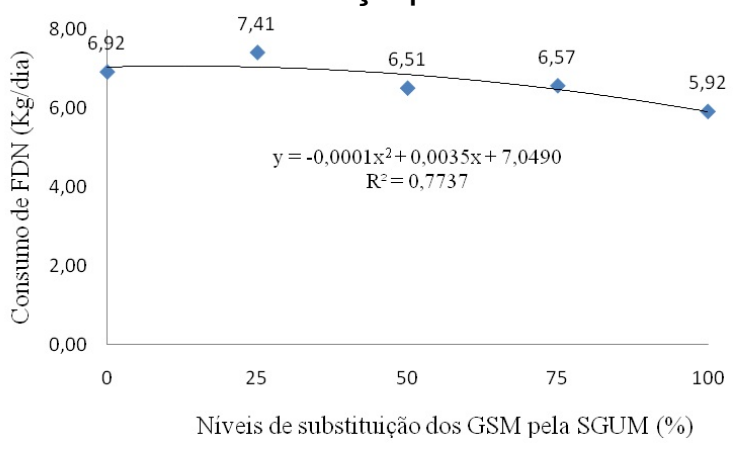

Figura 1 - CFDN com a inclusão da SGUM na dieta

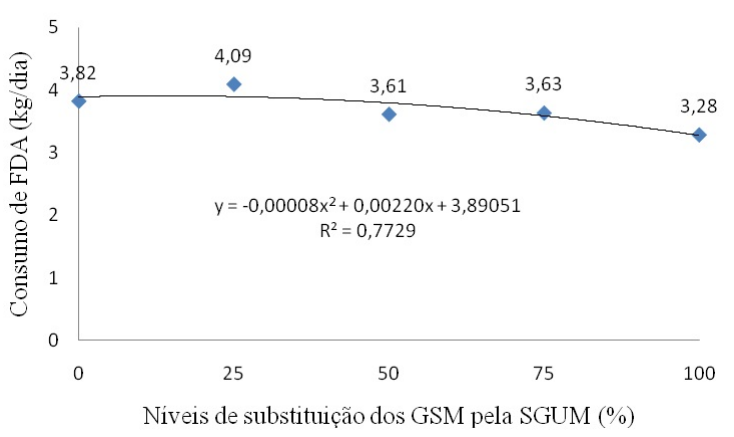

Figura 2 - CFDA com a inclusão da SGUM na dieta

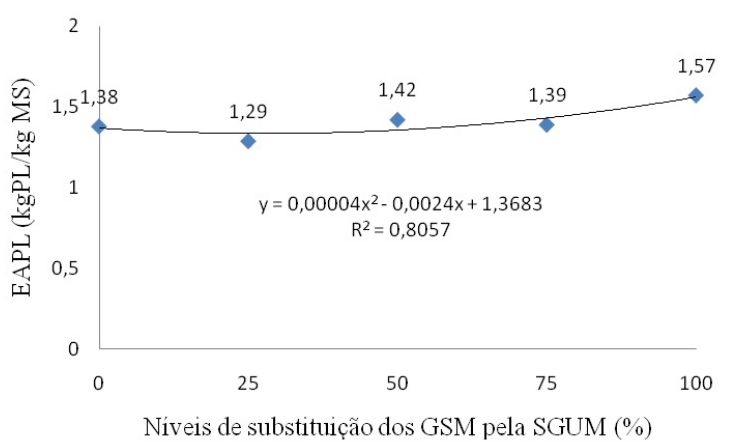

Figura 3 - EAPL com a inclusão da SGUM na dieta

Os resultados da composição e qualidade do leite encontram-se na Tabela 4. Com exceção do nitrogênio uréico, as demais características avaliadas não apresentaram efeito com a inclusão da SGUM nos tratamentos.

A não diferença dos tratamentos sobre o teor de gordura do leite (3,77\%) evidencia que a SGUM não deprime o mesmo, desde que a dieta esteja corretamente balanceada e a ingestão de fibra adequada. Como regra geral, níveis aceitáveis de gordura são observados quando a dieta contém $50 \%$ ou mais de forragem ou pelo menos $21 \%$ FDA e $28 \%$ FDN. É importante lembrar que o teor de gordura do leite é em parte, função da quantidade de precursores (acetato 17-45\% e betahidroxibutirato 8-25\%) disponíveis à glândula mamária para sintetizá-la (síntese de novo) enquanto outra parte é originada de ácidos graxos oriundos diretamente da dieta e/ou mobilizados da gordura corporal (González et al. 2001). Estes precursores são originados na fermentação dos alimentos no rúmen, em especial fibra.

Avaliando a alimentação de vacas com GSM e SGUM, Macleod et al. (1973) também não encontraram diferença para os teores de gordura do leite que foram respectivamente de 3,60 e $3,48 \%$. De igual forma, San Emeterio et al. (2000) não encontraram diferença para o teor de gordura do leite quando as vacas foram alimentadas com GSM, SGUM ou silagem de espigas de milho e duas formas de processamento dos grãos (grosseiramente moído e finamente moído), cujas médias foram 3,60 e 3,58; 3,49 e 3,$29 ; \quad 3,49$ e $3,25 \%$; respectivamente.

A proteína do leite tem sido mais valorizada atualmente que a gordura do leite em sistemas de pagamento, em virtude dos hábitos alimentares dos consumidores e por influir diretamente no rendimento industrial de derivados lácteos. Não houve efeito dos tratamentos sobre a proteína do leite $(3,22 \%)$, mesmo quando os GSM foram substituídos em $100 \%$ pela SGUM, já que esta sofre pouca variação nos seus componentes, oscilando de 0,3 a 0,4 unidades percentuais.

A excreção de proteína no leite é dependente do fluxo de proteína no intestino delgado e a principal fonte para o intestino delgado é a proteína microbiana, majoritariamente das bactérias ruminais. Assim, quanto mais aminoácidos forem absorvidos, mais substrato haverá para a síntese de caseínas e proteínas do leite (Mattos, 
2005). A síntese de proteína microbiana é dependente da disponibilidade de energia e esqueletos de carbono durante o metabolismo ruminal de carboidratos (Hall e Herejk, 2001). Carboidratos rapidamente fermentescíveis, como o amido, têm sido associados ao maior conteúdo de proteína no leite devido à maior energia disponível e à maior quantidade de propionato e proteína microbiana produzida (Jenkins e McGuire, 2005).

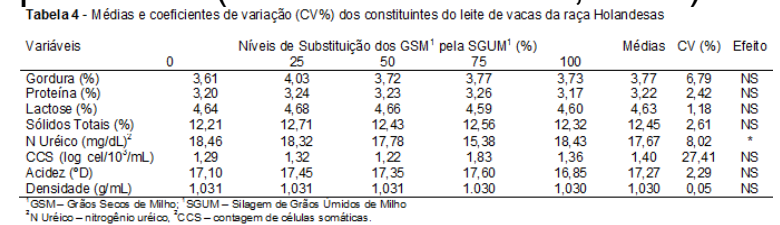

Resultados semelhantes foram encontrados por Macleod et al. (1973) que não encontraram diferença para proteína do leite quando as vacas foram alimentadas com GSM (3,03\%) e SGUM (3,01\%). Wilkerson et al. (1997), ao comparar GSM com SGUM e duas formas de processamento dos grãos (laminados ou moídos), não encontraram diferença para a proteína do leite, cujas médias foram 3,15 e 3,26; 3,21 e 3,26\%; respectivamente. O mesmo comportamento também foi observado por San Emeterio et al. (2000), quando forneceram GSM, SGUM e silagem de espiga de milho e duas formas de processamento dos grãos (grosseiramente moído e finamente moído), cujas médias foram 3,02 e 3,$05 ; 3,08$ e 2,$96 ; 3,03$ e $3,13 \%$; respectivamente.

A síntese de lactose é um dos mecanismos críticos para a vaca sustentar a produção, uma vez que a lactose é responsável pela drenagem de água para o alvéolo mamário, sendo esta a razão pela qual é o constituinte do leite com menor variação (Manson, 2003). No presente experimento não houve efeito dos tratamentos sobre a lactose que apresentou média de $4,63 \%$. Como relatado, a lactose se mantém praticamente constante entre as diferentes raças e quase inalterada por variações nutricionais, apesar de ser o principal glicídio do leite, um dissacarídeo composto pelos monossacarídeos D-glicose e D-lactose, ligados por uma ponte $\beta-1,4$. Dietas que são pobremente fermentadas diminuem a produção microbiana e os precursores para a produção de glicose e lactose no leite (Allen, 2001).

Confirmando os resultados deste experimento Macleod et al. (1973) não encontraram diferença para lactose quando as vacas foram alimentadas com GSM (5,95\%) e SGUM (5,12\%). Entretanto, Ekinci \& Broderick (1997), ao compararem SGUM $(4,71 \%)$ com silagem de espiga de milho (4,93\%) encontraram diferença para lactose.

A variação no teor de sólidos totais (gordura + proteína + lactose + cinzas) é, em grande parte dependente das variações no teor de gordura do leite, fração com maior amplitude de variação conforme já discutido. Todavia neste experimento não houve efeito dos tratamentos sobre o teor de sólidos totais do leite que apresentou média de $12,45 \%$.

O teor de nitrogênio uréico no leite (NUL) é influenciado pela ingestão de PB da dieta, pela fração da proteína degradável no rúmen e da proteína não degradável no rúmen, além da relação destas com a ingestão de energia (Broderick \& Clayton, 1997). Diante disso, o NUL tem sido utilizado como indicador para o monitoramento da nutrição protéica (Kohn, 2000), principalmente pela adequação da relação entre proteína e energia da dieta de vacas em lactação (Broderick \& Clayton, 1997). A concentração de ureia no sangue está altamente relacionada com a concentração de NUL (Bucholtz e Johson, 2007). Um alto conteúdo de NUL pode ser explicado pela menor energia de liberação dentro do rúmen, que limitaria 0 uso do nitrogênio produzido na fermentação ruminal e 

da raça holandesa em lactação

ocasionaria aumento na absorção de amônia.

Houve efeito dos tratamentos sobre o NUL (Figura 4) onde o menor valor foi observado com a dieta contendo $75 \%$ SGUM, isso pode estar relacionado ao efeito associativo entre os GSM e SGUM e com o melhor sincronismo entre a energia e a proteína da dieta. Garcia et al. (2010), observaram que a concentração de NUL foi menor nas vacas que consumiram silagem de grãos úmidos de milho comparada com as que receberam milho-grão seco moído, as vacas que consumiram silagem de grãos úmidos apresentaram mais baixos valores de NUL $(15,32 \mathrm{mg} / \mathrm{dL})$, e podem indicar que utilizaram mais eficientemente 0 nitrogênio. Aparentemente dietas com maior quantidade de amido de alta disponibilidade têm melhor utilização do nitrogênio.

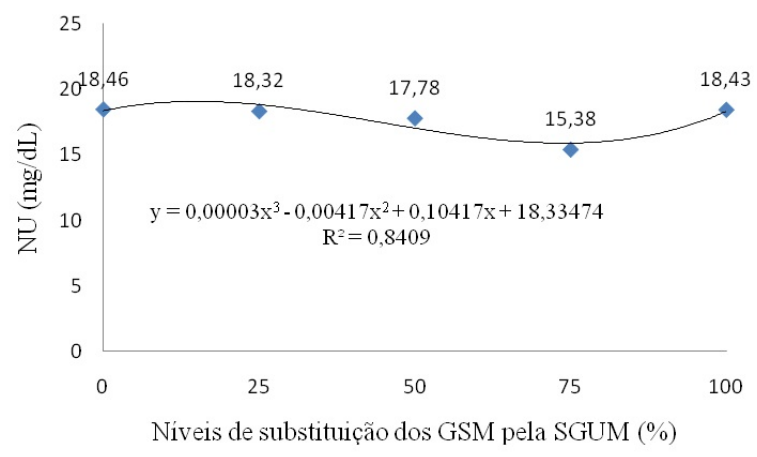

Figu ra 4- Nitrogênio uréico com a inclusão da SGUM na dieta

San Emeterio et al. (2000), comparando GSM com SGUM ou silagem de espigas de milho e duas formas de processamento dos grãos (grosseiramente moído e finamente moído), constataram que houve redução do NUL das vacas alimentadas com SGUM, refletindo em provável melhora na utilização de nitrogênio dentro do rúmen. Ekinci e Broderick (1997), ao compararem SGUM com silagem de espiga de milho e as mesmas com adição de farelo de soja, também encontraram diferença para o NUL, porém as maiores médias observadas foram com as dietas contendo adição de farelo de soja. Este resultado era esperado devido a mais alta ingestão de $\mathrm{PB}$, sendo consistente com a melhora na utilização do N.

Segundo Grant et al. (2007), o valor médio de NUL em um rebanho leiteiro deve estar entre $12-16 \mathrm{mg} / \mathrm{dL}$, respectivamente. Valores médios acima de $16 \mathrm{mg} / \mathrm{dL}$ indicariam deficiência na fermentação de carboidratos não fibrosos, excesso de proteína na dieta e/ou desequilíbrio entre as disponibilidades de energia e nitrogênio dentro do rúmen (Grant, 2005).

Entre os parâmetros de qualidade do leite em âmbito mundial a CCS tem sido utilizada pela grande maioria dos países, já que indica de maneira quantitativa o grau de infecção da glândula mamária que em animais sadios normalmente é menor que 200.000 células $/ \mathrm{mL}$ de leite (National Mastitis Council, 1996). A elevada CCS leva a menor concentração de caseína, gordura, lactose e potássio, e a maior concentração de proteínas do soro, sódio e cloro (Ribas, 1999), estas alterações na composição do leite acarretam graves problemas à indústria de laticínios. Quando há presença de células somáticas no leite são, normalmente, células de defesa do organismo que migram do sangue para o interior da glândula mamária, com o objetivo de combater os agentes causadores da mastite, podendo ser, também, células secretoras descamadas (Philpot e Nickerson, 1991).

No presente experimento não foi encontrado diferença para esta variável que apresentou média de 1,40 log cel $/ 10^{3} / \mathrm{mL}$, por causa da variabilidade entre as vacas, mas pode ter contribuído para o menor valor encontrado no NUL com a dieta contendo $75 \%$ de SGUM. Confirmando os dados Erinci \& Broderick (1997), ao avaliarem SGUM $\left(330 \times 10^{3}\right)$ e silagem de espigas de milho $\left(628 \times 10^{3}\right)$, 
concluíram que a CCS não diferiu entre os tratamentos por causa da variabilidade entre as vacas.

Quanto à acidez do leite vários fatores podem estar relacionados, tais como: genética, estágio da lactação, momento da ordenha, intervalo ordenha-análise, nutrição, sanidade, estresse calórico e diluição do leite. No presente experimento não foi encontrado diferença para a acidez do leite que apresentou média de $17,26^{\circ} \mathrm{D}$, estando dentro dos valores considerados normais que é $16-18^{\circ} \mathrm{D}$. Desta forma a SGUM pode ser substituída em até $100 \%$ sem alterar a mesma, já que é um parâmetro indicativo de qualidade, e desajustes podem resultar em penalidades aos produtores, pois o leite com maior acidez possui menor estabilidade ao calor. Por conseguinte, sob o ponto de vista nutricional a acidez do leite isoladamente tem pouco valor, mas sua relação com o teor de proteína do leite pode ser um indicio da adequação da nutrição protéica.

Não houve efeito dos tratamentos sobre a densidade do leite que apresentou valor médio de $1,030 \mathrm{~g} / \mathrm{mL}$, estando dentro dos valores considerados normais de 1,028 a 1,032 $\mathrm{g} / \mathrm{mL}$. Este teste é útil na detecção de adulteração do leite, uma vez que a adição de água causa diminuição da densidade, enquanto a retirada de gordura resulta em aumento da densidade. Sendo assim a água apresenta densidade de $1 \mathrm{~g} / \mathrm{mL}$, a gordura possui densidade abaixo desse valor, e a densidade final do leite dependerá do balanço desses componentes.

\section{CONCLUSÃO}

A silagem de grãos úmidos de milho pode ser utilizada na dieta de vacas em lactação em substituição total aos grãos secos de milho, sem alterar o
CMS, produção e composição do leite. Também se mostrou mais eficiente e proporcionou melhor aproveitamento dos nutrientes da dieta total.

\section{REFERÊNCIAS}

ALLEN, M. Formulating lactating cows diets for carbohydrates. In: WESTERN DAIRY

MANAGEMENT CONFERENCE, 5., 2001, Las Vegas. Proceedings... Las Vegas, 2001. p.7986.

\section{ASSOCIATION OF OFFICIAL ANALYTICAL CHEMISTRY - AOAC Official methods of analysis. 12.ed. Washington: AOAC, 1990. 1117p.}

BRODERICK, G.A.; MERTENS, D.R.; SIMONS $R$. Efficacy of carbohydrate sources of milk production by cows fed diets based on alfalfa silage. Journal of Dairy Science, v.85, n.7, p.1767-1776, 2002.

BUCHOLTZ, H.; JOHNSON, T. Use of milk urea nitrogen in herd management. In: ANNUAL TRISTATE DAIRY NUTRITION CONFERENCE, 16., 2007, Fort Wayne. Proceedings... Fort Wayne, 2007. p.63-67.

CHANDLER, P.T.; MILLER, C.N.; JAHN, E. Feeding value and nutrient preservation of high moisture corn ensiled in conventional silos for lactating dairy cows. Journal of Dairy Science, v.58, n.5, p.682-688, 1974.

CLARK, J.H.; CROOM, W.J.; HARSHBARGER, K.E. Feeding value of dry, ensiled, and acid treated high moisture corn fed whole or rolled to lactating cows. Journal of Dairy Science, v.58, n.6, p.907-916, 1974.

CLARK, J.H.; HARSHBARGER, K.E. High moisture corn versus dry corn in combination with either corn silage or hay for lactating cows. Journal of Dairy Science, v.55, n.10, p.4741480, 1972.

EKINCI, C.; BRODERICK, G.A. Effect of processing moisture ear corn on ruminal fermentation and milk yield. Journal of Dairy Science, v.80, n.12, p.3296-3307, 1997.

GRANT, R.J.; DRUDICK, D.; KEOWN, J.F. Milk urea nitrogen testing. Lincoln: IANR University of Nebraska. Disponível em: http://www.ianrpubs.unl.edu/dairy/g1298. ht/m>. Acessado em 20 nov 2007. 
GRANT, R.J. Optimizing starch concentrations in dairy rations. In: ANNUAL TRI-STATE DAIRY NUTRITION CONFERENCE, 14., 2005, Fort Wayne. Proceedings... Fort Wayne, 2005. p.73-79.

GARCÍA, G.A.G., REIS, R.B. ; PEREIRA, A.B.D. et al. Produção e composição do leite de vacas em pastagem de capim-elefante (Pennisetum purpureum) suplementado com diferentes fontes de carboidratos. Arquivo Brasileiro de Medicina Veterinária e Zootecnia, v.62, n.4, p.875-882, 2010

GONZÁLEZ, F.H.D.; DÜRR, J.W.I. Uso do leite para monitorar a nutrição e o metabolismo de vacas leiteiras. Biblioteca Setorial da Faculdade de Medicina Veterinária da UFRGS, 2001.

HALL, M.B.; HEREJK, C. Differences in yields of microbial crude protein from in vitro fermentation of carbohydrates. Journal of Dairy Science, v.84, p.2486, 2001

JASPER, S.P.; SEKI, A.S.; BIAGGIONI, M.A.M; et al. Comparação econômica da produção de grãos secos e silagem de grãos úmidos de milho cultivado em sistema de plantio direto. Ciência e Agrotecnologia, v.33, n.5, set./out. 2009.

JENKINS, T.C.; McGUIRE, M.A. Effects of nutrition on milk composition: A 25-year review of research reported in the journal of Journal of Dairy Science. In: ANNUAL TRI-STATE DAIRY NUTRITION CONFERENCE, 14., 2005, Fort Wayne. Proceedings... Fort Wayne, 2005. p.51-57.

JOBIM, C.C.; BRANCO, A.F.; SANTOS, G.T. Silagem de grãos úmidos na alimentação de bovinos leiteiros. In: SIMPÓSIO GOIANO SOBRE MANEJO E NUTRIÇÃO DE BOVINOS DE CORTE E LEITE, 5., 2003, Goiânia. Anais... Goiânia: CNBA, 2003. p.357-376.

MACLEOD, G.K.; GRIVE, D.G.; FREEMAN, M.G. Performance of dairy cows fed acid-treated high moisture shelled corn. Journal of Dairy Science, v.57, n.4, p.439-442, 1973.

MANSON, S. 2003. How the cow makes lactose. Disponívelem:<http://www.westerndairyscience. com> Acesso em: 17/07/09

MATTOS, W. Influência da nutrição sobre a composição de sólidos totais no leite. In: SIMPÓSIO SOBRE BOVINOCULTURA LEITEIRA, 5., 2005, Piracicaba. Anais... Piracicaba, 2005.
NATIONAL MASTITIS COUNCIL. Current concepts of bovine mastitis. 4.ed. Madison : National Mastitis Council, 1996. 64p.

NATIONAL RESEARCH COUNCIL - NRC. Nutrient requirements of dairy cattle, seventh revised edition. Washington: National Academy Press, 2001. 381p.

OBA, M.; ALLEN, M.S. Effects of corn grain conservation method on feeding behavior and productivity of lactating dairy cows at two dietary starch concentrations. Journal of Dairy Science, v.86, p.174-183, 2003.

OWENS, F.N.; ZINN, R.A.; KIM, Y.K. Limits to starch digestion in the ruminant small intestine. Journal of Dairy Science, v.63, n.3, p.16341648, 1986.

PHILPOT, W.N., NICKERSON, S.C. 1991. Mastitis: counter attack. Naperville: Babson Bros. 150p.

RIBAS, N. P. Importância da contagem de células somáticas para a saúde da glândula mamária e qualidade do leite. In: INTERLEITE SIMPÓSIO INTERNACIONAL SOBRE PRODUÇÃO INTENSIVA DE LEITE, 4., CAXAMBU, 1999. Anais... São Paulo, 1999. p.77-87.

SAN EMETERIO, F.; REIS, R.B.; CAMPOS, W.E. et al. Effect of coarse or fine grinding on utilization of dry or ensiled corn by lactating dairy cows. Journal of Dairy Science, v.83, n.12, p.2839-2848, 2000.

STATISTICAL ANALYSES SYSTEM - SAS. Users' guide: statistics. 5.ed. Cary: 1996, 955p.

Van SOEST, P.J.; ROBERTSON J.B.; LEWIS B.A. Methods for dietary fiber, neutral detergent fiber, and nonstarch polysaccharides in relation to animal nutrition. Journal of Dairy Science, v.74, n.10, p.3583-3597, 1991.

WILKERSON, V.A.; GLENN, B.P.; MCLEOD, K.R. Energy and nitrogen balance in lactating cows fed diets containing dry or high moisture corn in either rolled or ground form. Journal of Dairy Science, v.80. n.10, p.2487-2496, 1997. 